\title{
Trinitrobenzene sulfonic acid-induced intestinal injury in neonatal mice activates transcriptional networks similar to those seen in human necrotizing enterocolitis
}

\author{
Krishnan MohanKumar', Kopperuncholan Namachivayam', Feng Cheng' ${ }^{2,3}$, Rays H.Y. Jiang ${ }^{4}$, Jaime Flores-Torres ${ }^{1}$, \\ Benjamin A. Torres' and Akhil Maheshwari ${ }^{1,5,6}$
}

\begin{abstract}
BACKGROUND: We have shown previously that enteral administration of 2, 4, 6-trinitrobenzene sulfonic acid in 10-dold C57BL/6 pups produces an acute necrotizing enterocolitis with histopathological and inflammatory changes similar to human necrotizing enterocolitis (NEC). To determine whether murine neonatal 2, 4, 6-trinitrobenzene sulfonic acid (TNBS)mediated intestinal injury could be used as a NEC model, we compared gene expression profiles of TNBS-mediated intestinal injury and NEC.
\end{abstract}

METHODS: Whole-genome microarray analysis was performed on proximal colon from control and TNBS-treated pups ( $n=8 /$ group). For comparison, we downloaded human microarray data of NEC $(n=5)$ and surgical control $(n=4)$ from a public database. Data were analyzed using the software programs Partek Genomics Suite and Ingenuity Pathway Analysis. RESULTS: We detected extensive changes in gene expression in murine TNBS-mediated intestinal injury and human NEC. Using fold-change cut-offs of \pm 1.5 , we identified 4,440 differentially-expressed genes (DEGs) in murine TNBS-mediated injury and 1,377 in NEC. Murine TNBS-mediated injury and NEC produced similar changes in expression of orthologous genes $(r=0.611, P<0.001)$, and also activated nearly-identical biological processes and pathways. Lipopolysaccharide was top predicted upstream regulator in both the murine and human datasets.

CONCLUSION: Murine neonatal TNBS-mediated enterocolitis and human NEC activate nearly-identical biological processes, signaling pathways, and transcriptional networks.

$\mathbf{N}$ ecrotizing enterocolitis (NEC) continues to be a leading cause of mortality in premature neonates born prior to 32 wk gestation (1). The pathogenesis of NEC is complex and not well-understood; epidemiological studies associate NEC with risk factors ranging from chorioamnionitis, perinatal asphyxia, indomethacin therapy, formula feedings, human milk fortifiers, viral infections, feed thickeners, to severe anemia and/or consequent red blood cell transfusions (2). However, a unifying pathophysiological mechanism remains elusive.

In recent years, several clinical studies have shown that the incidence of NEC peaks in premature infants at a postmenstrual age (gestational age at birth + postnatal age) equivalent to $32 \mathrm{wk}$ gestation (3-5). Considering this developmental predilection, and because clinical antecedents of NEC seem too diverse, we have argued that the pathoanatomy of NEC represents a generic injury response of the intestine during a certain developmental epoch, rather than mirroring specific causal mechanism(s) $(6,7)$. To investigate this hypothesis, we induced inflammatory intestinal injury in 10-d-old murine pups by using 2, 4, 6-trinitrobenzene sulfonic acid (TNBS) as a nonspecific immunological insult that causes mucosal injury in the presence of the intestinal microflora (6). TNBS-induced murine neonatal enterocolitis was marked by monocyte/macrophage-rich infiltrates and extensive necrosis, and therefore, showed a strong histopathological resemblance to human NEC $(6,7)$.

In the present study, we used microarray technology to obtain a panoramic view of the gene networks in murine neonatal TNBS-mediated intestinal injury and human NEC. We integrated genetic, biological, and functional information to delineate differentially-expressed genes (DEGs), gene interactions and transcriptional networks. To determine whether this murine model could, at least in part, recapitulate human NEC, we also compared the murine and human datasets for dysregulated pathways/processes and their upstream regulators.

\section{RESULTS}

Microarray Profiles of TNBS-Mediated Murine Neonatal Intestinal Injury and Human NEC

Administration of TNBS in C57BL/6 pups induced severe inflammatory changes and tissue necrosis in distal ileum and

\footnotetext{
'Department of Pediatrics, Morsani College of Medicine, University of South Florida, Tampa, Florida; ${ }^{2}$ Department of Pharmaceutical Science, College of Pharmacy, University of South Florida, Tampa, Florida; ${ }^{3}$ Department of Epidemiology and Biostatistics, College of Public Health, University of South Florida, Tampa, Florida; ${ }^{4}$ Department of Global Health, College of Public Health, University of South Florida, Tampa, Florida; ${ }^{5}$ Department of Molecular Medicine, Morsani College of Medicine, University of South Florida, Tampa, Florida; ${ }^{6}$ Department of Community and Family Health, College of Public Health, University of South Florida, Tampa, Florida. Correspondence: Akhil Maheshwari (akhilm@health.usf.edu)

Received 19 May 2016; accepted 26 July 2016; advance online publication 19 October 2016. doi:10.1038/pr.2016.189
} 


\section{Articles $\mid$ MohanKumar etal.}

proximal colon. We used the first $0.5 \mathrm{~cm}$ of the proximal colon for microarray analysis. Principal component analysis of these microarrays accounted for $62.7 \%$ of the variability in gene expression and revealed distinct clustering of gene expression in the TNBS-treated and control intestine (Figure 1a). Similarly, principal component analysis of datasets from human NEC and uninflamed human neonatal intestine showed that the two groups also aggregated in distinct clusters (Figure 1b). In NEC, principal component analysis accounted for $75.7 \%$ of the variability in gene expression.

\section{DEGs in TNBS-Mediated Intestinal Injury and Human NEC}

We next compared the signal intensities of genes in murine TNBS-mediated intestinal injury and control, and in human NEC vs. uninflamed neonatal intestine. Using fold-change cut-offs of $\pm 1.5, P$-value $<0.05$ (in analysis of variance), and a false discovery rate of $5 \%$, we identified 4,440 DEGs in murine TNBS-mediated injury out of a total of 39,601 probe sets. As shown in Figure 2a (top panel), 1,648 genes were upregulated in TNBS-mediated intestinal injury, whereas 2,792 genes were expressed at higher levels in control. Hierarchical clustering of these DEGs showed distinct expression profiles in the control and injury groups (bottom panel). The heat maps also highlighted that only a minority of DEGs were upregulated in intestinal injury.

In human NEC, we detected a similar pattern of gene expression. Using filters similar to the murine datasets, we identified 1377 DEGs out of a total of 33,297 probe sets. As shown in Figure 2b, 324 genes were upregulated in NEC, whereas 1,053 genes were overexpressed in the uninflamed neonatal intestine. Hierarchical clustering confirmed distinct gene expression profiles in NEC and uninflamed intestine, and similar to TNBS-mediated injury, showed that only a small group of genes was upregulated in the NEC intestine.

We have listed DEGs in TNBS-mediated intestinal injury and NEC by functional categories in Table 1 . To restrict this list to a smaller, more meaningful length, we chose thresholds $\geq \pm 2$-fold with $P<0.01$. The top 10 upregulated and downregulated genes are listed in Table 2 . A complete listing of the DEGs in TNBS-mediated intestinal injury and NEC is provided as Supplementary Tables S1 and S2 online, respectively.

To determine whether the transcriptional changes in murine TNBS-mediated intestinal injury model human NEC, we compared our murine and human datasets for the direction and intensity of change in gene expression. To circumvent the difficulties in comparing across species and microarray platforms, we extracted the data on the orthologous genes from our list of DEGs (Supplementary Table S3 online). As shown in Figure 3, these 484 genes showed a high degree of concordance in expression and were similarly up- or downregulated in TNBS-mediated injury and human NEC, respectively (Spearman's $r=0.611, P<0.001$ ).

\section{Biological Processes Active in Murine TNBS-Mediated Intestinal Injury and Human NEC}

We next used the software program Partek Genomic Suite to map DEGs to Biological Process categories of Gene Ontology (GO) (8) and to rank these GO categories by enrichment score (computed as the negative natural log of the $P$ value). In both murine TNBS-mediated intestinal injury and NEC, the top
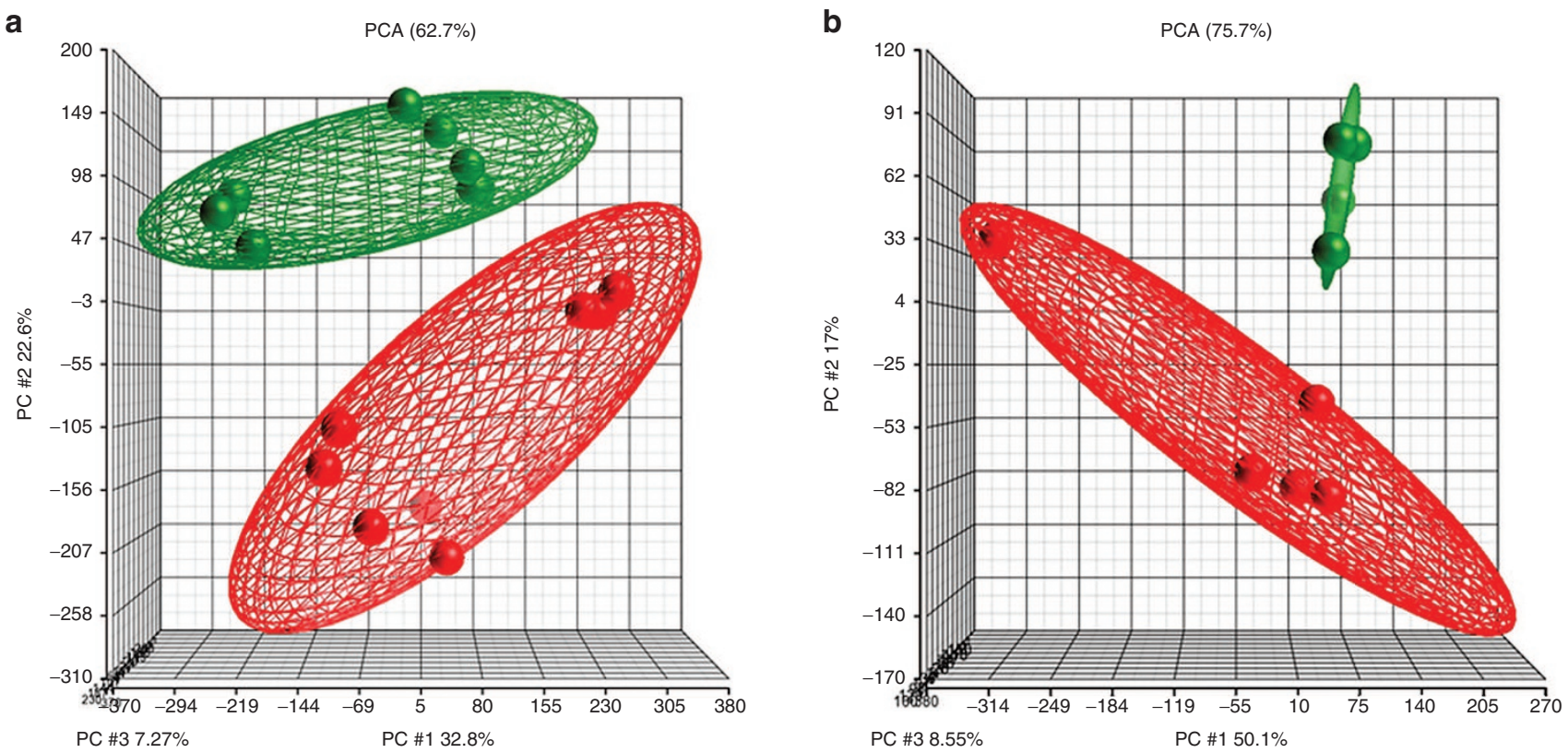

Figure 1. Microarray profiles of 2, 4, 6-trinitrobenzene sulfonic acid (TNBS)-mediated murine neonatal intestinal injury and human necrotizing enterocolitis (NEC): (a) Principal component analysis (PCA) of microarray data from control (green) and TNBS-treated mice (red) showed distinct clustering of the two groups. $N=8$ pups/group. The graph is a scatter plot of the values of three principal components based on the correlation matrix of the total normalized array intensity data; each point represents one animal. Ellipsoids represent $95 \%$ confidence intervals of the clusters. X-, Y-, and Z-axis correspond to principal component 1 (PC1), PC2, and PC3; (b) PCA of datasets from uninflamed human neonatal intestine (green) and NEC (red) show that these two groups also aggregated in separate clusters. $N=5$ patients with NEC, four controls with uninflamed intestine. 
a
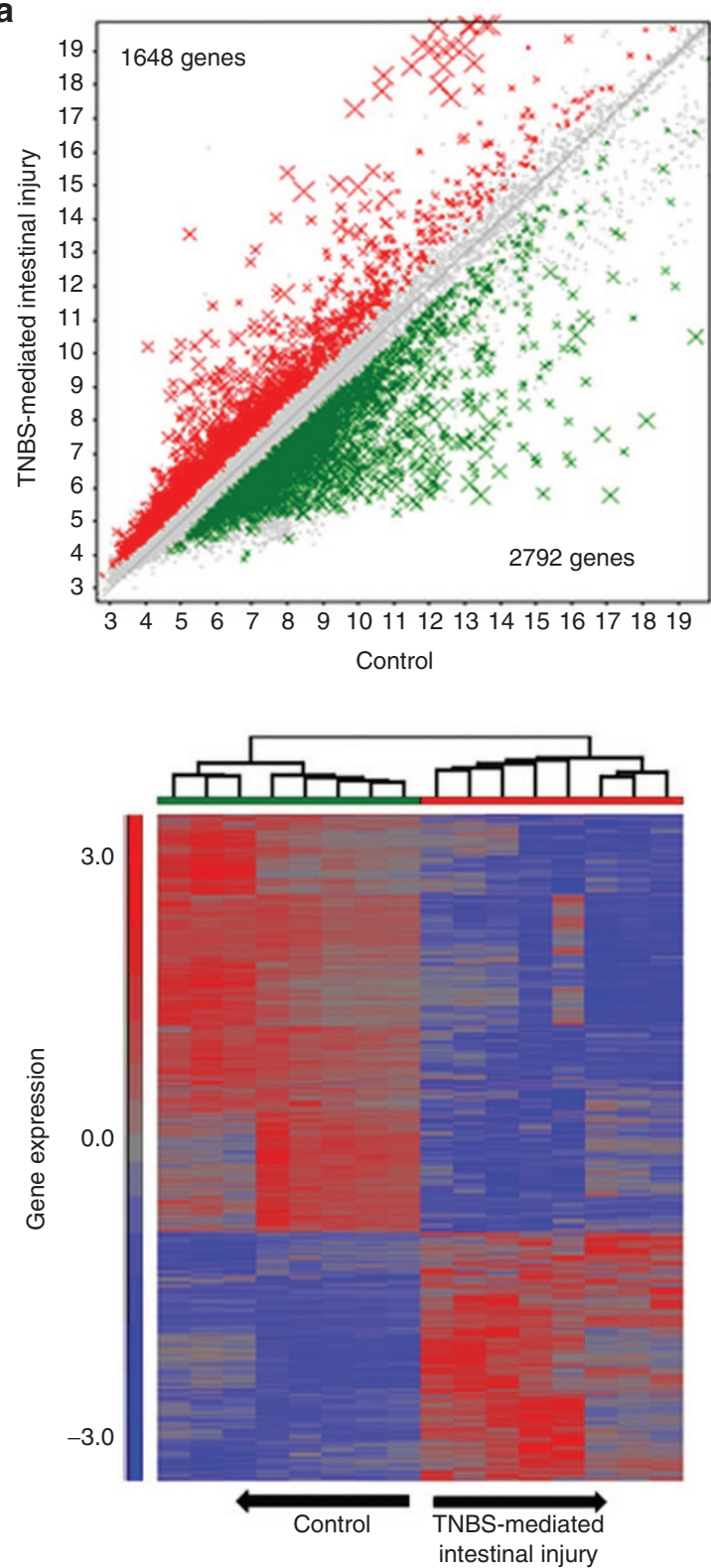

b
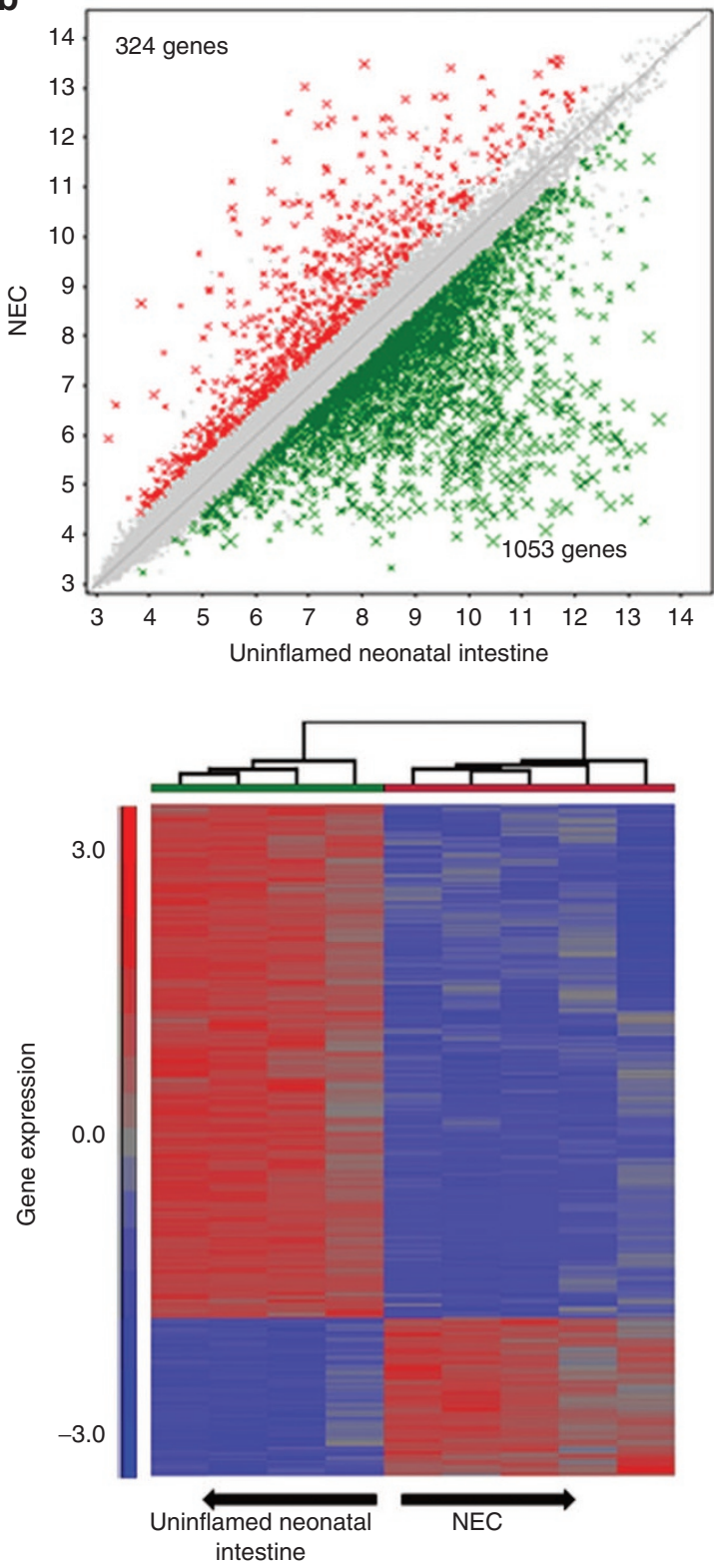

Figure 2. Differentially-expressed genes (DEGs) in 2, 4, 6-trinitrobenzene sulfonic acid (TNBS)-mediated intestinal injury and human necrotizing enterocolitis (NEC): (a) DEGs in murine TNBS-mediated intestinal injury vs. control. Top: Scatterplot shows DEGs upregulated in intestinal injury (red) and control (green). Each gene is denoted by an $\mathrm{X}$, the size of which is inversely proportional to the $\mathrm{p}$-value. $\mathrm{X}$ - and $\mathrm{Y}$-axis show signal intensities on a log, scale. Data were analyzed by ANOVA. Grey marks indicates genes that were filtered out; Bottom: Hierarchical clustering of DEGs in TNBS-mediated injury vs. control highlights the distinct gene expression profiles of the two groups. Dendrogram above the heat map depicts hierarchical clustering of the samples (controls shown as green, injury samples red). Cluster distance is based on the average distance between all the pairs of objects in the two clusters. Dendrograms for DEGs are not depicted. In the heat maps, red shows increased expression, blue indicates decreased expression, whereas grey shows no change. Expression value intensities are illustrated by color with a range of -3 to +3 on a log scale; (b) DEGs in human NEC and uninflamed neonatal intestine. Top: Scatterplot shows genes upregulated in NEC (red) and uninflamed intestine (green); Bottom: Hierarchical clustering of DEGs shows distinct profiles of human NEC and uninflamed intestine. Settings similar to panel $\mathbf{a}$.

biological processes were cellular processes (enrichment scores of 91.26 and 86.1, respectively) and single-organism processes (enrichment scores of 77.67 and 74.59 , respectively). As shown in Figure 4a, the biological process activated in murine TNBSmediated intestinal injury and human NEC were nearly identical.

Histopathologically, inflammation and tissue necrosis are the hallmarks of NEC. Therefore, we focused on two GO Biological Process categories: the immune system and cell death. The top immune system processes identified in both TNBS-mediated injury and human NEC were leukocyte migration (enrichment scores of 15.88 and 19.39, respectively) and immune response (enrichment scores of 11.62 and 7.95, respectively; Figure $4 \mathrm{~b}$ ). The primary cellular process leading to cell death in both TNBS-mediated intestinal injury and human NEC was programmed cell death/apoptosis (enrichment scores of 14.26 and 3.61, respectively; Figure 4c). 


\section{Articles | MohanKumar et al.}

Table 1. Differentially-expressed genes in TNBS-mediated murine neonatal intestinal injury and human NEC

\begin{tabular}{|c|c|c|c|c|c|}
\hline \multicolumn{3}{|c|}{ TNBS-mediated murine intestinal injury } & \multicolumn{3}{|c|}{ Human NEC } \\
\hline Gene symbol (mouse) & $\begin{array}{l}\text { Fold-change (intestinal } \\
\text { injury vs. control) }\end{array}$ & $\begin{array}{l}P \text {-value (intestinal } \\
\text { injury vs. control) }\end{array}$ & $\begin{array}{l}\text { Gene symbol } \\
\text { (human) }\end{array}$ & $\begin{array}{l}\text { Fold-change (NEC vs. } \\
\text { uninflamed intestine) }\end{array}$ & $\begin{array}{l}P \text {-value (NEC } \\
\text { vs. uninflamed } \\
\text { intestine) }\end{array}$ \\
\hline Ly6g & 25.3817 & $2.03 \mathrm{E}-10$ & CD177 & 46.1533 & $1.06 \mathrm{E}-5$ \\
\hline Ly6a & 9.6089 & $2.09 \mathrm{E}-9$ & TREM1 & 24.328 & $8.65 \mathrm{E}-6$ \\
\hline $\operatorname{ltg} 55$ & 2.01284 & 8.44E-4 & FPR1 & 9.15378 & $1.32 \mathrm{E}-4$ \\
\hline \multirow[t]{4}{*}{ Cd14 } & 2.23735 & $1.33 \mathrm{E}-4$ & C5AR1 & 9.07387 & $1.85 \mathrm{E}-4$ \\
\hline & & & TLR2 & 7.46131 & $1.9 \mathrm{E}-4$ \\
\hline & & & CD163 & 4.59848 & $1.03 \mathrm{E}-3$ \\
\hline & & & TLR4 & 2.91104 & $5.57 \mathrm{E}-4$ \\
\hline \multicolumn{6}{|c|}{ Calcium-binding proteins } \\
\hline $5100 a 8$ & 13.4153 & $5.30 \mathrm{E}-8$ & $\mathrm{~S} 100 \mathrm{~A} 12$ & 28.1327 & $5.63 \mathrm{E}-5$ \\
\hline S100a9 & 7.59614 & $3.90 \mathrm{E}-8$ & S100A9 & 14.4051 & $1.15 \mathrm{E}-4$ \\
\hline S100a14 & 3.09206 & $1.76 \mathrm{E}-4$ & S100A8 & 11.1661 & $7.72 \mathrm{E}-5$ \\
\hline S100a11 & 2.4841 & $1.85 \mathrm{E}-3$ & S100A11 & 2.01031 & $4.02 \mathrm{E}-4$ \\
\hline S100a6 & 2.53026 & $4.32 \mathrm{E}-3$ & S100A14 & -3.66239 & $7.91 \mathrm{E}-5$ \\
\hline S100g & -8.39296 & $1.16 \mathrm{E}-9$ & & & \\
\hline \multicolumn{6}{|l|}{ Solute carriers } \\
\hline Slc51a & -6.06685 & $5.78 \mathrm{E}-6$ & SLC5A12 & -44.8826 & $3.72 \mathrm{E}-5$ \\
\hline Slc34a2 & -6.00088 & $6.84 \mathrm{E}-5$ & $\mathrm{SLC} 2 \mathrm{~A} 2$ & -37.4188 & $3.38 \mathrm{E}-6$ \\
\hline Slc40a1 & -5.86264 & $4.44 \mathrm{E}-8$ & SLC15A1 & -27.8306 & $4.85 \mathrm{E}-5$ \\
\hline Slc5a8 & -5.50916 & 1.37E-7 & SLC44A4 & -27.4277 & $1.14 \mathrm{E}-6$ \\
\hline Slc10a5 & -5.49049 & 4.03E-9 & SLC6A19 & -26.6032 & $1.43 \mathrm{E}-6$ \\
\hline Slc6a19 & -4.48791 & $1.91 \mathrm{E}-4$ & SLC7A9 & -13.9373 & $6.63 \mathrm{E}-5$ \\
\hline Slc15a1 & -4.43097 & $1.72 \mathrm{E}-9$ & & & \\
\hline Slc7a8 & -4.0919 & $2.89 \mathrm{E}-8$ & & & \\
\hline \multicolumn{6}{|c|}{ Cytokines, chemokines, and cognate receptors } \\
\hline $\mathrm{CxCl} 2$ & 6.34927 & $1.25 \mathrm{E}-6$ & IL1A & 41.982 & $2.75 \mathrm{E}-4$ \\
\hline $1 / 1 b$ & 3.92428 & $2.88 \mathrm{E}-5$ & IL1B & 41.2998 & $1.59 \mathrm{E}-5$ \\
\hline $\mathrm{CCl} 2$ & 3.46452 & $6.03 \mathrm{E}-5$ & CXCL8 & 35.6662 & $8.81 \mathrm{E}-6$ \\
\hline $1 / 1 r n$ & 5.13162 & 5.77E-8 & IL6 & 25.798 & 2.67E-5 \\
\hline Tnfrsf12a & 3.13015 & $5.24 \mathrm{E}-8$ & IL1R2 & 24.1338 & 7.33E-4 \\
\hline $\mathrm{Cxcl3}$ & 2.78899 & $9.78 \mathrm{E}-7$ & CCL3 & 13.7709 & $2.84 \mathrm{E}-4$ \\
\hline Cxcl5 & 2.67758 & $5.26 \mathrm{E}-5$ & CCL3L3 & 12.3779 & $6.11 \mathrm{E}-4$ \\
\hline $\mathrm{Ccl} 7$ & 2.90073 & $6.31 \mathrm{E}-5$ & IL1RN & 12.3734 & $1.94 \mathrm{E}-3$ \\
\hline
\end{tabular}

Table 1. Continued on next page 
Table 1. Continued

\begin{tabular}{|c|c|c|c|c|c|}
\hline \multicolumn{3}{|c|}{ TNBS-mediated murine intestinal injury } & \multicolumn{3}{|c|}{ Human NEC } \\
\hline Gene symbol (mouse) & $\begin{array}{l}\text { Fold-change (intestinal } \\
\text { injury vs. control) }\end{array}$ & $\begin{array}{l}P \text {-value (intestinal } \\
\text { injury vs. control) }\end{array}$ & $\begin{array}{l}\text { Gene symbol } \\
\text { (human) }\end{array}$ & $\begin{array}{l}\text { Fold-change (NEC vs. } \\
\text { uninflamed intestine) }\end{array}$ & $\begin{array}{c}P \text {-value (NEC } \\
\text { vs. uninflamed } \\
\text { intestine) }\end{array}$ \\
\hline $\mathrm{CCl} 3$ & 2.71695 & $4.71 \mathrm{E}-4$ & CCL4L2 & 10.7223 & $8.41 \mathrm{E}-4$ \\
\hline $111 r 2$ & 2.48661 & $9.60 \mathrm{E}-7$ & $\mathrm{CXCL2}$ & 9.75128 & $1.89 \mathrm{E}-5$ \\
\hline$\| 1 r 1$ & 2.47906 & $5.11 \mathrm{E}-7$ & CCL4L2 & 9.1063 & $1.16 \mathrm{E}-3$ \\
\hline Vip & 4.50863 & $2.17 \mathrm{E}-5$ & $\mathrm{CXCL} 1$ & 7.75825 & $2.17 \mathrm{E}-4$ \\
\hline $1 / 19$ & 2.43878 & $3.63 \mathrm{E}-4$ & FGF7 & 3.6188 & $9.70 \mathrm{E}-6$ \\
\hline $1 / 1 a$ & 2.3335 & $7.82 \mathrm{E}-4$ & ANGPT2 & 3.52358 & $1.94 \mathrm{E}-3$ \\
\hline Cxcl1 & 2.33307 & 4.77E-5 & $\mathrm{CXCL3}$ & 2.83887 & 3.03E-4 \\
\hline Pf4 & 2.02541 & $4.38 \mathrm{E}-5$ & IL1R1 & 2.82136 & $1.50 \mathrm{E}-4$ \\
\hline Fgf15 & -5.60601 & $4.54 \mathrm{E}-7$ & $\mathrm{CCL} 2$ & 2.75979 & $1.62 \mathrm{E}-4$ \\
\hline Tnfsf10 & -2.08014 & $1.96 \mathrm{E}-6$ & CCL25 & -15.5371 & $2.14 \mathrm{E}-6$ \\
\hline $\mathrm{Cc} 2121 a$ & -4.07594 & $8.36 \mathrm{E}-6$ & CXCL14 & -12.6101 & $5.75 \mathrm{E}-4$ \\
\hline$C c / 21 b$ & -3.8607 & $1.41 \mathrm{E}-5$ & & & \\
\hline \multicolumn{6}{|l|}{ Enzyme inhibitors } \\
\hline Serpina3n & 9.00078 & $3.30 \mathrm{E}-8$ & SERPINB2 & 55.8164 & $2.15 \mathrm{E}-4$ \\
\hline Timp1 & 4.50872 & $1.44 \mathrm{E}-7$ & SERPINE1 & 9.21821 & $1.49 \mathrm{E}-3$ \\
\hline Serpina3g & 2.31019 & $3.88 \mathrm{E}-6$ & TIMP1 & 3.27933 & $1.65 \mathrm{E}-4$ \\
\hline Serpine1 & 2.2178 & $1.42 \mathrm{E}-4$ & & & \\
\hline \multicolumn{6}{|l|}{ Enzymes } \\
\hline Mmp3 & 4.18699 & $2.78 \mathrm{E}-6$ & MMP8 & 18.5117 & $7.16 \mathrm{E}-4$ \\
\hline Mmp10 & 3.30835 & $2.47 \mathrm{E}-5$ & ADAMTS9 & 3.33943 & $1.13 \mathrm{E}-3$ \\
\hline Adam8 & 2.25568 & $1.22 \mathrm{E}-5$ & MMP14 & 2.47711 & $1.67 \mathrm{E}-3$ \\
\hline \multicolumn{6}{|l|}{ Immune mediators } \\
\hline Stfa2 & 4.27652 & $1.38 \mathrm{E}-6$ & IRAK3 & 7.06643 & $1.03 \mathrm{E}-4$ \\
\hline Gp49a & 4.39035 & $1.97 \mathrm{E}-7$ & NLRC4 & 6.09349 & $6.13 \mathrm{E}-4$ \\
\hline Thbs 1 & 4.24043 & $1.22 \mathrm{E}-5$ & TNFAIP3 & 4.87626 & $1.01 \mathrm{E}-3$ \\
\hline Stfa3 & 3.34135 & $4.61 \mathrm{E}-6$ & SIGLEC5 & 4.87278 & $1.89 \mathrm{E}-3$ \\
\hline Stfa1 & 3.56203 & $1.27 \mathrm{E}-5$ & IL1RAP & 3.83477 & $4.49 \mathrm{E}-4$ \\
\hline Stfa2/1 & 12.0136 & $1.29 \mathrm{E}-7$ & THBS1 & 2.93907 & $1.54 \mathrm{E}-3$ \\
\hline $\mathrm{Saa3}$ & 3.18986 & $1.68 \mathrm{E}-8$ & NFKBIA & 2.64241 & $8.93 \mathrm{E}-4$ \\
\hline \multicolumn{6}{|l|}{ Transcription factors } \\
\hline Hif1a & 2.55804 & $6.22 \mathrm{E}-6$ & CEBPB & 3.48237 & $3.11 \mathrm{E}-4$ \\
\hline Cebpd & 4.16739 & $4.01 \mathrm{E}-8$ & HIF1A & 2.29961 & $3.5 \mathrm{E}-3$ \\
\hline Cebpb & 2.03583 & $1.25 \mathrm{E}-3$ & RUNX1 & 2.31259 & $1.2 \mathrm{E}-3$ \\
\hline Fos & 2.03438 & 4.47E-7 & CEBPG & -2.00683 & $5.5 \mathrm{E}-4$ \\
\hline Runx1 & 1.98006 & $5.50 \mathrm{E}-7$ & & & \\
\hline \multicolumn{6}{|l|}{ Apolipoproteins } \\
\hline Apoa4 & -10.143 & $3.98 \mathrm{E}-4$ & APOB & -93.8819 & $5.06 \mathrm{E}-7$ \\
\hline Apob & -15.3669 & $1.15 \mathrm{E}-4$ & APOA4 & -65.5193 & $1.46 \mathrm{E}-7$ \\
\hline \multirow[t]{2}{*}{ Apoa1 } & -5.47609 & $8.82 \mathrm{E}-4$ & APOC3 & -25.3508 & $6.08 \mathrm{E}-6$ \\
\hline & & & APOA1 & -11.5383 & $8.7 \mathrm{E}-4$ \\
\hline \multicolumn{6}{|l|}{ Cytochrome proteins } \\
\hline Cyp2c55 & -56.9722 & $5.15 \mathrm{E}-11$ & CYP3A4 & -144.116 & $3.45 \mathrm{E}-6$ \\
\hline Cyp2d26 & -18.5949 & $2.20 \mathrm{E}-13$ & CYP2B6 & -27.1438 & $8.53 \mathrm{E}-6$ \\
\hline Cyp2c65 & -9.70339 & $2.07 \mathrm{E}-8$ & CYP3A5 & -23.9293 & $5.91 \mathrm{E}-5$ \\
\hline Сурза13 & -6.83871 & $1.79 \mathrm{E}-6$ & CYP2C9 & -12.0691 & $1.86 \mathrm{E}-4$ \\
\hline Cyp2w1 & -6.15221 & $7.43 \mathrm{E}-8$ & & & \\
\hline Сур2с66 & -5.87623 & $1.15 \mathrm{E}-8$ & & & \\
\hline Сур2с68 & -4.31912 & $8.58 \mathrm{E}-9$ & & & \\
\hline
\end{tabular}




\section{Articles | MohanKumar et al.}

Table 2. Top 10 up- and downregulated genes in murine TNBS-mediated neonatal intestinal injury and human NEC Murine TNBS-mediated intestinal injury: Top 10 upregulated genes

\begin{tabular}{|c|c|c|c|c|}
\hline Serial No. & Gene & Gene name & Fold change & $P$-value \\
\hline 1. & Ly6g & Lymphocyte antigen 6 complex, locus G & 25.3817 & $2.03 \mathrm{E}-10$ \\
\hline 2. & $5100 a 8$ & S100 calcium binding protein $\mathrm{A} 8$ (calgranulin $\mathrm{A}$ ) & 13.4153 & $5.30 \mathrm{E}-8$ \\
\hline 3. & Stfa2l1 & Stefin A2 like 1 & 12.0136 & $1.29 \mathrm{E}-7$ \\
\hline 4. & Ly6a & Lymphocyte antigen 6 complex, locus A & 9.6089 & 2.09E-9 \\
\hline 5. & Gm12840 & Predicted gene, 12840 & 9.01718 & 4.87E-11 \\
\hline 6. & Serpina3n & Serine (or cysteine) peptidase inhibitor, clade $\mathrm{A}$, member $3 \mathrm{~N}$ member $3 \mathrm{~N}$ & 9.00078 & $3.30 \mathrm{E}-8$ \\
\hline 7. & Gm3776 & Predicted gene, 3776 & 8.30097 & $7.78 \mathrm{E}-8$ \\
\hline 8. & Akr1b8 & Aldo-keto reductase family 1 , member $B 8$ & 7.7098 & $9.22 \mathrm{E}-8$ \\
\hline 9. & $5100 a 9$ & S100 calcium binding protein A9 (calgranulin B) & 7.59614 & $3.90 \mathrm{E}-8$ \\
\hline 10. & Slc7a11 & Solute carrier family 7 member 11 & 7.18376 & 3.21E-8 \\
\hline
\end{tabular}

Murine TNBS-mediated intestinal injury:Top 10 downregulated genes

\begin{tabular}{|c|c|c|c|c|}
\hline 1. & Сур2c55 & Cytochrome P450, family 2, subfamily c, polypeptide 55 & -56.9722 & $5.15 \mathrm{E}-11$ \\
\hline 2. & Car1 & Carbonic anhydrase 1 & -32.9199 & $1.28 \mathrm{E}-9$ \\
\hline 3. & Gm5843 & Predicted gene, 5843 & -27.9322 & $8.64 \mathrm{E}-10$ \\
\hline 5. & 1810065E05Rik & RIKEN cDNA 1810065 E05 gene & -20.0201 & $5.38 \mathrm{E}-9$ \\
\hline 6. & Сур2d26 & Cytochrome P450, family 2, subfamily d, polypeptide 26 & -18.5949 & $2.20 \mathrm{E}-13$ \\
\hline 9. & Naaladl1 & $\mathrm{N}$-acetylated alpha-linked acidic dipeptidase-like 1 & -15.9323 & $1.64 \mathrm{E}-5$ \\
\hline 10. & Apob & Apolipoprotein B & -15.3669 & $1.15 \mathrm{E}-4$ \\
\hline \multicolumn{5}{|c|}{ Human NEC:Top 10 upregulated genes } \\
\hline 1. & SERPINB2 & Serpin family B member 2 & 55.8164 & $2.15 \mathrm{E}-4$ \\
\hline 5. & CXCL8 & $\mathrm{C}-\mathrm{X}-\mathrm{C}$ motif chemokine ligand 8 & 35.6662 & $8.81 \mathrm{E}-6$ \\
\hline 6. & $A Q P 9$ & Aquaporin 9 & 30.183 & $7.25 \mathrm{E}-5$ \\
\hline 7. & S100A12 & S100 calcium binding protein $\mathrm{A} 12$ & 28.1327 & $5.63 \mathrm{E}-5$ \\
\hline 8. & IL6 & Interleukin 6 & 25.798 & 2.67E-5 \\
\hline 9. & TREM1 & Triggering receptor expressed on myeloid cells 1 & 24.328 & $8.65 \mathrm{E}-6$ \\
\hline 10. & IL1R2 & Interleukin 1 receptor 2 & 24.1338 & 7.33E-4 \\
\hline \multicolumn{5}{|c|}{ Human NEC:Top 10 downregulated genes } \\
\hline 1. & СYР3A4 & Cytochrome P450 family 3 subfamily A member 4 & -144.116 & $3.45 \mathrm{E}-6$ \\
\hline 2. & $S I$ & Sucrase-isomaltase & -132.797 & $4.59 \mathrm{E}-6$ \\
\hline 9. & TM4SF20 & Transmembrane $4 \mathrm{~L}$ six family member 20 & -86.7135 & 4.10E-7 \\
\hline 10. & $L C T$ & Lactase & -83.0787 & $1.12 \mathrm{E}-5$ \\
\hline
\end{tabular}

NEC, necrotizing enterocolitis; TNBS, 2, 4, 6-trinitrobenzene sulfonic acid. 


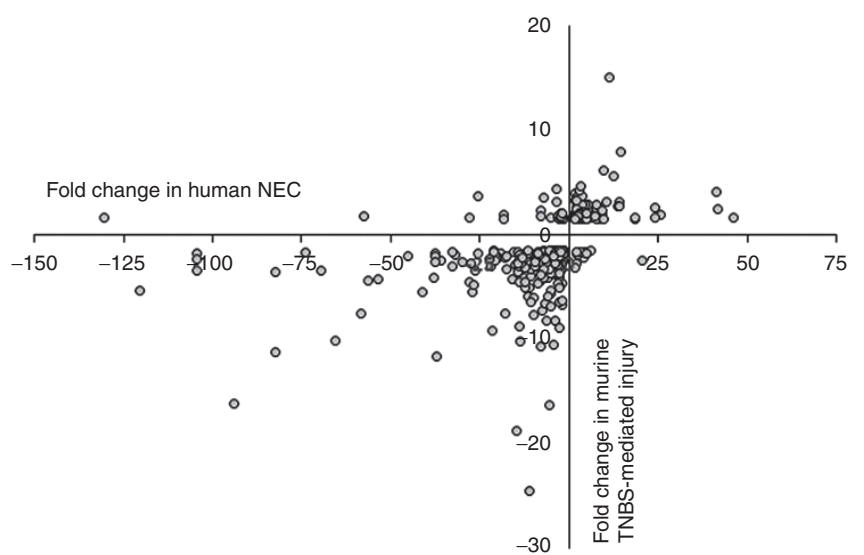

Figure 3. Murine 2, 4, 6-trinitrobenzene sulfonic acid (TNBS)-mediated intestinal injury and human necrotizing enterocolitis (NEC) show similar changes in gene expression: Scatter-plot shows changes in the expression of orthologous genes in the human and murine intestine in NEC and TNBS-mediated intestinal injury, respectively. $X$-axis shows fold changes in human genes during NEC on a $\log _{2}$ scale, whereas the $Y$-axis shows changes in their murine orthologues during TNBS-mediated intestinal injury. Most data points were clustered in the top right (upregulated in both human NEC and murine intestinal injury) or bottom left quadrants (downregulated in both datasets) of the XY plane, indicating that the expression of these orthologous genes changed similarly in murine TNBS-mediated intestinal injury and human NEC.

\section{Disease-Related Pathways Active in Murine TNBS-Mediated Injury and Human NEC}

We next used the online software application Ingenuity Pathway Analysis (IPA) to map DEGs into disease-related GO pathways. Top canonical pathways activated in TNBSmediated intestinal injury were similar to those see in human NEC (Table 3).

We also evaluated top inflammatory and cell death pathways in our murine and human datasets, utilizing the KEGG databases (9) with pathway enrichment tools within the software program Partek Pathway and in the Database for Annotation, Visualization and Integrated Discovery (DAVID) (10). Tumor necrosis factor (TNF)-activated signaling, hematopoietic cell signaling, cytokine-cytokine receptor interaction, nucleotide-binding oligomerization domain receptor (NOD-like receptor)-mediated signaling, and chemokine signaling pathways were enriched in both TNBS-mediated intestinal injury and human NEC (Table 4).

To compare the mechanism(s) of mucosal inflammation and cell death in murine TNBS-mediated intestinal injury and human NEC, we evaluated the murine and human datasets for DEGs active in the top inflammatory pathways (TNF signaling, hematopoietic cell signaling, and cytokine-cytokine receptor interaction; Figure 5) and in promoting apoptosis. Several key mediators were common to both murine TNBSmediated injury and human NEC (highlighted in orange): interleukin (IL)-1 $\alpha$, IL-1 $\beta$, IL-1 receptor 1 (IL1R1), IL1R2, IL-6, TNF receptor superfamily member 1B (TNFRSF1B)/ TNFR2, TNF $\alpha$-induced protein 3 (TNFAIP3)/A20, IL18R1, transforming growth factor- $\beta_{3}$, TNF superfamily, member 10 (TNFSF10)/TNF-related apoptosis-inducing ligand (TRAIL); chemokines CXC-motif ligand (CXCL)-1, CXCL2, CXCL3, CXCL5, CC-motif ligand (CCL)-2, CCL3, leukocyte receptors CD14, integrin $\alpha \mathrm{M}$ (ITGAM)/CD11b, colony stimulating factor receptor (CSFR)-2b; the transcription factor CCAAT/ Enhancer Binding Protein (C/EBP)- $\beta$, enzymes such as prostaglandin-endoperoxide synthase 2 (PTGS2) and alanyl aminopeptidase (ANPEP), and signaling mediators such as suppressor of cytokine signaling 3 (SOCS3), and nuclear factor of kappa light polypeptide gene enhancer in B-cells inhibitor, $\alpha$ (NFKBIA)/inhibitor of $\kappa \mathrm{B}-\alpha(\mathrm{I} \kappa \mathrm{B} \alpha)$. In the apoptotic pathways, IL- $1 \alpha$, IL $1 \beta$, IL1R1, I $\mathrm{B} \alpha$, and IL1R-associated kinase 3 (IRAK3) were enriched in both murine TNBS-mediated intestinal injury and human NEC (not depicted).

\section{Comparison Analysis of Murine TNBS-Mediated Injury and Human NEC}

We next used Ingenuity Pathway Analysis to compare murine and human datasets for canonical GO pathways, upstream transcriptional regulators, and disease processes typically mediated by the observed transcriptional networks. Heat maps developed by hierarchical clustering of DEGs showed that the top canonical pathways were enriched to similar degree in murine TNBS-mediated intestinal injury and human NEC (Figure 6a). In both datasets, lipopolysaccharide (LPS)/IL-1 mediated inhibition of RXR function, granulocyte adhesion and diapedesis, activation of nuclear receptors, xenobiotic metabolism signaling (including activation of aryl hydrocarbon receptors), IL-12 and IL-17 signaling, and Toll-like receptor activation was enriched. Similarly, the predicted upstream regulators also showed remarkable similarity; LPS, TNF, IL- $1 \beta$, interferon (IFN) $-\gamma$, and IL- 6 were the top transcriptional regulators in both the murine and human datasets (Figure 6b). In both datasets, the top GO disease processes were inflammatory response, necrosis, apoptosis, and leukocyte migration (Figure 6c), which also happen to be the major histopathological findings in human NEC (11). In NEC lesions, existing evidence documents apoptosis mainly in intestinal epithelial cells and not in other cell lineages (12), and consistent with these data, we detected transcriptional networks that were generally consistent with apoptosis but not those typical of cell death in antigen-presenting cells or the connective tissue.

\section{LPS Is Predicted to Activate Similar Transcriptional Networks in Both Murine TNBS-Mediated Injury and Human NEC}

LPS was identified as a top upstream transcriptional regulator in both TNBS-mediated intestinal injury and human NEC. Interestingly, the predicted transcriptional networks activated by LPS in the murine and human datasets were nearly identical (Figure 7); in these networks, LPS was predicted to induce IL-1 $\beta$, IL-6, TNF, and IFN- $\gamma$, which, in turn, activated the transcription factors nuclear factor- $\kappa \mathrm{B}-1$ (NF- $\kappa \mathrm{B} 1)$, signal transducer and activator of transcription (STAT)-3, and $c$-Jun. STAT1 and I $\mathrm{B} \alpha$ were predicted to dampen these inflammatory cascades. $\mathrm{C} / \mathrm{EBP}-\beta$ activation was predicted with greater confidence in NEC than in murine intestinal injury. Tumor 


\section{Articles $\mid$ MohanKumaretal.}

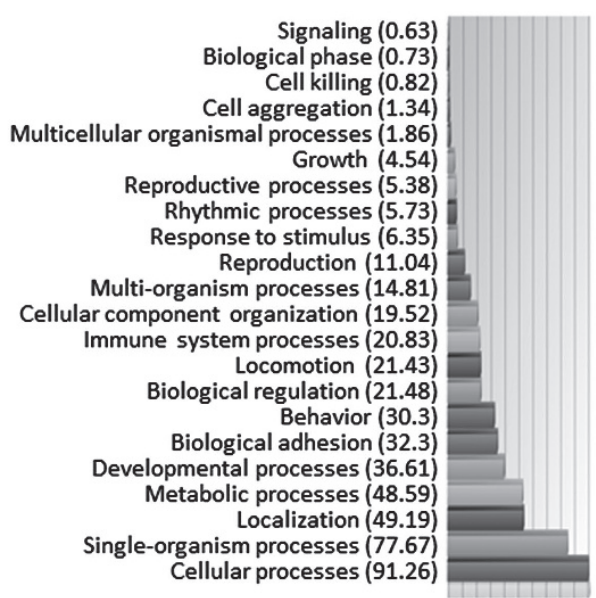

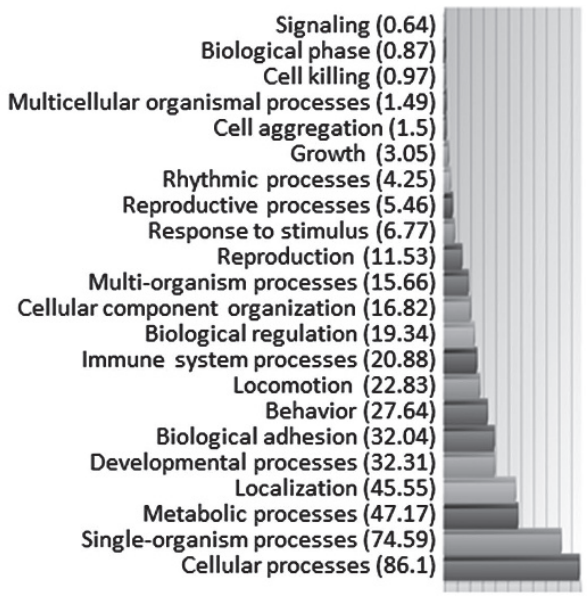

b

Somatic diversification of immune receptors $(0.1)$ T-cell selection (0.28) B-cell selection (1.36) Tolerance induction (1.43) Lymphocyte co-stimulation (3.19) Myeloid cell homeostasis (3.32) Antigen processing and presentation (4.41) Leukocyte homeostasis (4.62)

Production of molecular immune mediators (5.07) Activation of immune response (5.07) Leukocyte activation (5.62) Immune effector process (8.7) Immune response (11.62 Leukocyte migration (15.88)

C

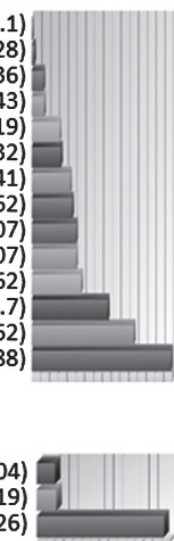

Somatic diversification of immune receptors $(0.06)$ Antigen processing and presentation $(0.08)$ Lymphocyte co-stimulation (0.36) Leukocyte homeostasis (1.08) Tolerance induction (1.71)

Immune effector process (1.72) Activation of immune response (1.75) Leukocyte activation (3) Myeloid cell homeostasis (3.12) Production of molecular immune mediators (3.28) Immune response (7.95) Leukocyte migration (19.39)
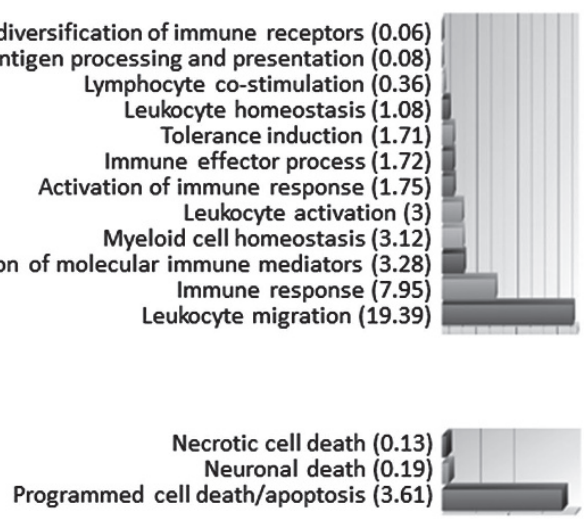

Figure 4. Top biological processes in murine 2, 4, 6-trinitrobenzene sulfonic acid (TNBS)-mediated intestinal injury and human necrotizing enterocolitis (NEC): (a) Bar diagrams show the top biological processes activated in TNBS-mediated intestinal injury (left) and human NEC (right). The predicted GO categories were ranked by enrichment score [-log ( $p$-value)]. Single-organism processes included various cellular, metabolic, developmental, and reproductive processes. Multi-organism processes included response to bacteria or other organisms; (b) Bar diagrams show immune system processes activated in TNBS-mediated injury (left) and human NEC (right); (c) Bar diagrams show biological processes leading to cell death in TNBS-mediated injury (left) and human NEC (right).

protein 53 (tp53)/p53 was predicted to limit TNBS-mediated injury but these interactions did not reach statistical significance in NEC. In contrast, glucocorticoid receptor (nuclear receptor subfamily 3 , group C, member $1 / \mathrm{NR} 3 \mathrm{C} 1$ ) was identified as a likely inhibitor in human NEC but not in murine intestinal injury.

\section{DISCUSSION}

We present a detailed comparison of the transcriptional networks activated in murine neonatal TNBS-mediated intestinal injury and human NEC, and show a high degree of similarity between the two datasets in terms of DEGs and predicted biological processes, pathways, and the causal networks. These observations are consistent with our previous reports that TNBS-mediated intestinal injury in mouse pups resembled human NEC in both the cellular inflammatory response and cytokine/chemokine expression in the affected intestine $(6,7)$. In this context, the present study provides additional evidence suggesting that murine neonatal TNBS-mediated intestinal injury could be useful in modeling human NEC in preclinical studies.
We have previously described the use of TNBS to induce acute necrotizing enterocolitis in mouse pups (6). We postulated that the pathoanatomy of NEC represents a generic injury response of the developing intestine (6), and therefore, used TNBS as a non-specific, but predictable, immunological insult to induce bowel injury in pups. The temporal course and pathoanatomy of TNBS-induced intestinal injury in pups recapitulates several clinical characteristics of human NEC, and differs considerably from TNBS-induced colitis in adult mice (13) (Table 5). Our rationale for using TNBS to simulate NEC-like injury in mouse pups was as follows: (i) TNBS had been used successfully to induce colitis in adult mice to model inflammatory bowel disease (7); (ii) TNBS administration in pups by gavage and enema produced inflammatory injury in the distal ileum and colon, and recapitulated the regional predilection of human NEC. The cellular inflammatory response was comprised of monocyte/macrophage-rich infiltrates and also resembled NEC (6); (iii) TNBS did not affect germ-free mice, indicating that the mucosal injury occurred only in the presence of gut bacteria (similar to NEC) and was not due to chemical/corrosive action of TNBS (6); (iv) TNBS-mediated 
Table 3. Top canonical pathways activated in murine TNBS-mediated neonatal intestinal injury and human NEC

Murine TNBS-mediated neonatal intestinal injury

\begin{tabular}{|c|c|c|c|}
\hline Name & $\begin{array}{l}\text { Enrichment } \\
\text { score }\end{array}$ & $P$ value & Overlap \\
\hline $\begin{array}{l}\text { LPS/IL-1 mediated } \\
\text { inhibition of RXR } \\
\text { function }\end{array}$ & 12.665 & $2.16 \mathrm{E}-13$ & $31.6 \%(61 / 193$ genes $)$ \\
\hline $\begin{array}{l}\text { Granulocyte adhesion } \\
\text { and diapedesis }\end{array}$ & 8.297 & $5.05 \mathrm{E}-9$ & $29.5 \%$ (44/149 genes) \\
\hline $\begin{array}{l}\text { Agranulocyte adhesion } \\
\text { and diapedesis }\end{array}$ & 7.275 & $5.31 \mathrm{E}-8$ & $27.5 \%$ (44/160 genes) \\
\hline PXR/RXR activation & 7.001 & $9.97 \mathrm{E}-8$ & $40 \%(22 / 55$ genes $)$ \\
\hline LXR/RXR activation & 6.356 & 4.41E-7 & $29.9 \%$ (32/107 genes) \\
\hline \multicolumn{4}{|l|}{ Human NEC } \\
\hline Name & $\begin{array}{l}\text { Enrichment } \\
\text { score }\end{array}$ & $P$-value & Overlap \\
\hline $\begin{array}{l}\text { LPS/IL-1 mediated } \\
\text { inhibition of RXR } \\
\text { function }\end{array}$ & 16.854 & $1.4 \mathrm{E}-17$ & $35.7 \%(79 / 221$ genes $)$ \\
\hline $\begin{array}{l}\text { Granulocyte adhesion } \\
\text { and diapedesis }\end{array}$ & 15.241 & $5.74 \mathrm{E}-16$ & $37.3 \%(66 / 177$ genes $)$ \\
\hline FXR/RXR activation & 11.065 & $8.61 \mathrm{E}-12$ & $37.3 \%$ (47/126 genes) \\
\hline $\begin{array}{l}\text { Xenobiotic metabolism } \\
\text { signaling }\end{array}$ & 10.78 & $1.66 \mathrm{E}-11$ & $28.6 \%$ (78/273 genes) \\
\hline $\begin{array}{l}\text { Agranulocyte adhesion } \\
\text { and diapedesis }\end{array}$ & 9.495 & $3.2 \mathrm{E}-10$ & $30.7 \%$ (58/189 genes) \\
\hline
\end{tabular}

FXR, farnesoid X receptor; LPS, lipopolysaccharide; NEC, necrotizing enterocolitis; RXR, retinoid X receptor; TNBS, 2, 4, 6-trinitrobenzene sulfonic acid.

enterocolitis can be used to investigate the temporal evolution of neonatal intestinal injury (from the time of instillation of TNBS), unlike the hypothermia-hypoxia model where individual animals develop bowel injury at different times during the NEC protocol $(14,15)$; (v) comparison of pups vs. adult mice treated with weight-normalized doses of TNBS can provide insights into the developmental aspects of NEC; (vi) unlike NEC models involving splanchnic ischemia-reperfusion or the administration of platelet-activating factor where the animals need to be euthanized within a few hours $(16,17)$, the evolution of TNBS-enterocolitis can be observed over longer periods; (vii) because all pups in a cohort are affected predictably, fewer animals are needed (compared to the hypoxia-hypothermia model where bowel injury may occur only in $40-70 \%$ mice); and (viii) the use of 10-d-old pups allows enough time to test prophylactic interventions; it was convenient that the rodent intestine at birth resembles the preterm human intestine and takes $3 \mathrm{wk}$ to reach the structural/functional maturity of the term human neonate $(18,19)$.

The number of DEGs in our murine samples was much larger than in the human datasets. We suspect that many genes in the human dataset did not rise to statistical significance because of clinical variability. In our mouse model, intestinal tissue was harvested from a predefined bowel region from all animals at one specific time-point, and was compared to controls that were identical in region, postnatal age, genetic background,
Table 4. Top inflammatory pathways activated in murine TNBSmediated neonatal intestinal injury and human NEC

Murine TNBS-mediated neonatal intestinal injury

\begin{tabular}{|c|c|c|c|}
\hline Name & $\begin{array}{l}\text { Enrichment } \\
\text { score }\end{array}$ & $P$ value & Overlap \\
\hline TNF signaling & 9.749 & $5.83 \mathrm{E}-5$ & $27.1 \%$ (29/107 genes) \\
\hline $\begin{array}{l}\text { NOD-like receptor } \\
\text { signaling }\end{array}$ & 8.067 & $3.13 \mathrm{E}-4$ & $31 \%$ (18/58 genes) \\
\hline $\begin{array}{l}\text { Hematopoietic cell } \\
\text { signaling }\end{array}$ & 7.263 & 7.01E-4 & $34.4 \%$ (22/82 genes) \\
\hline $\begin{array}{l}\text { Cytokine-cytokine } \\
\text { receptor interaction }\end{array}$ & 6.941 & $9.66 \mathrm{E}-4$ & $20.1 \%(52 / 258$ genes $)$ \\
\hline $\begin{array}{l}\text { Chemokine } \\
\text { signaling }\end{array}$ & 3.221 & 4.11E-2 & $16.7 \%(32 / 192$ genes $)$ \\
\hline \multicolumn{4}{|l|}{ Human NEC } \\
\hline Name & $\begin{array}{l}\text { Enrichment } \\
\text { score }\end{array}$ & $P$-value & Overlap \\
\hline TNF signaling & 8.381 & $2.29 \mathrm{E}-4$ & $23.6 \%$ (26/84 genes) \\
\hline $\begin{array}{l}\text { Cytokine-cytokine } \\
\text { receptor interaction }\end{array}$ & 8.260 & $2.58 \mathrm{E}-4$ & $18.8 \%(50 / 266$ genes $)$ \\
\hline $\begin{array}{l}\text { NOD-like receptor } \\
\text { signaling }\end{array}$ & 6.495 & $1.51 \mathrm{E}-3$ & $26.3 \%$ (15/57 genes) \\
\hline $\begin{array}{l}\text { Chemokine } \\
\text { signaling }\end{array}$ & 4.798 & $8.24 \mathrm{E}-3$ & $35.7 \%$ (15/42 genes) \\
\hline $\begin{array}{l}\text { Hematopoietic cell } \\
\text { signaling }\end{array}$ & 2.659 & $6.01 \mathrm{E}-2$ & $17.2 \%$ (15/87 genes) \\
\hline
\end{tabular}

diet, and environment with the exception of TNBS exposure. In contrast, patients with NEC underwent surgical resection at different gestational and postnatal ages, and at different time-points following onset of NEC. These NEC specimens were compared to control tissue samples that were not obviously inflamed but were also not entirely normal (those infants underwent abdominal surgery for intestinal obstruction or ileostomy repair), and were only approximately comparable in gestational and postnatal age to the NEC group. In addition to these sources of variability, some other clinical issues also merit consideration. With improved supportive care, it is often possible to delay surgery in some infants until after the acute phase has passed (20). In the interim, some of the early changes in gene expression in the affected bowel may subside and may no longer be detectable in surgically-resected samples. Finally, we must consider the possibility of variable RNA yield from surgical samples of NEC. During surgery for acute NEC, visual identification of necrotic bowel from areas of borderline viability can be a challenging task. Cognizant of the risks of short bowel syndrome, most surgeons take a conservative approach and limit resection to the most-obviously devitalized segments (21). Therefore, surgically-resected specimens of NEC often include patches that are completely necrotic with limited transcriptional activity.

The top immune system process in both TNBS-mediated intestinal injury and human NEC was leukocyte migration. 


\section{Articles | MohanKumar et al.}

a

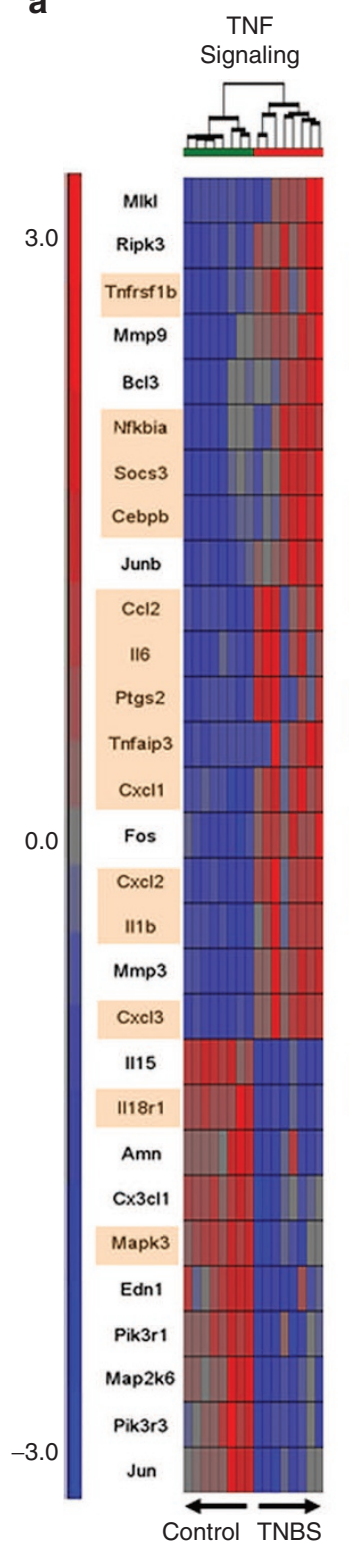

Hematopoietic cells

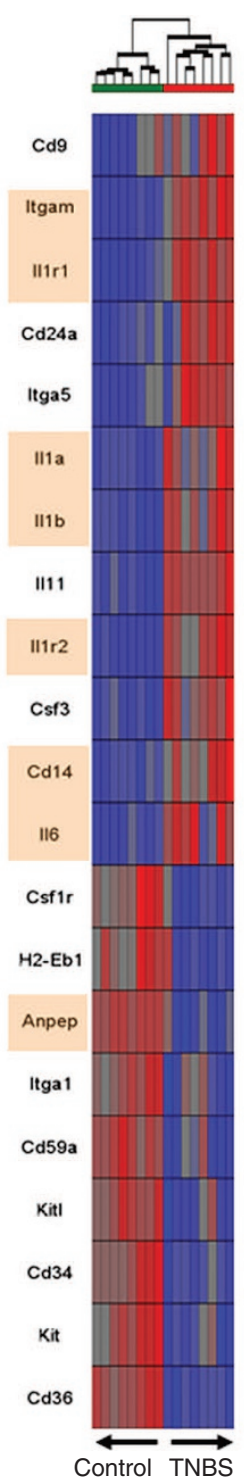

Cytokine-receptor interaction

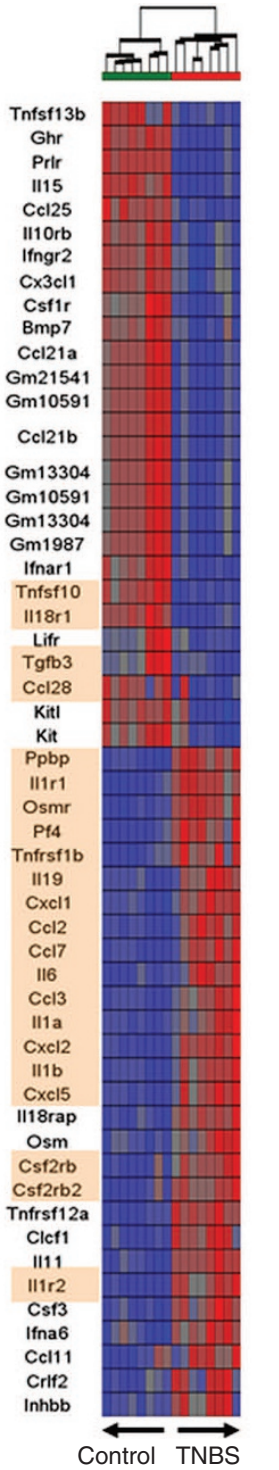

b

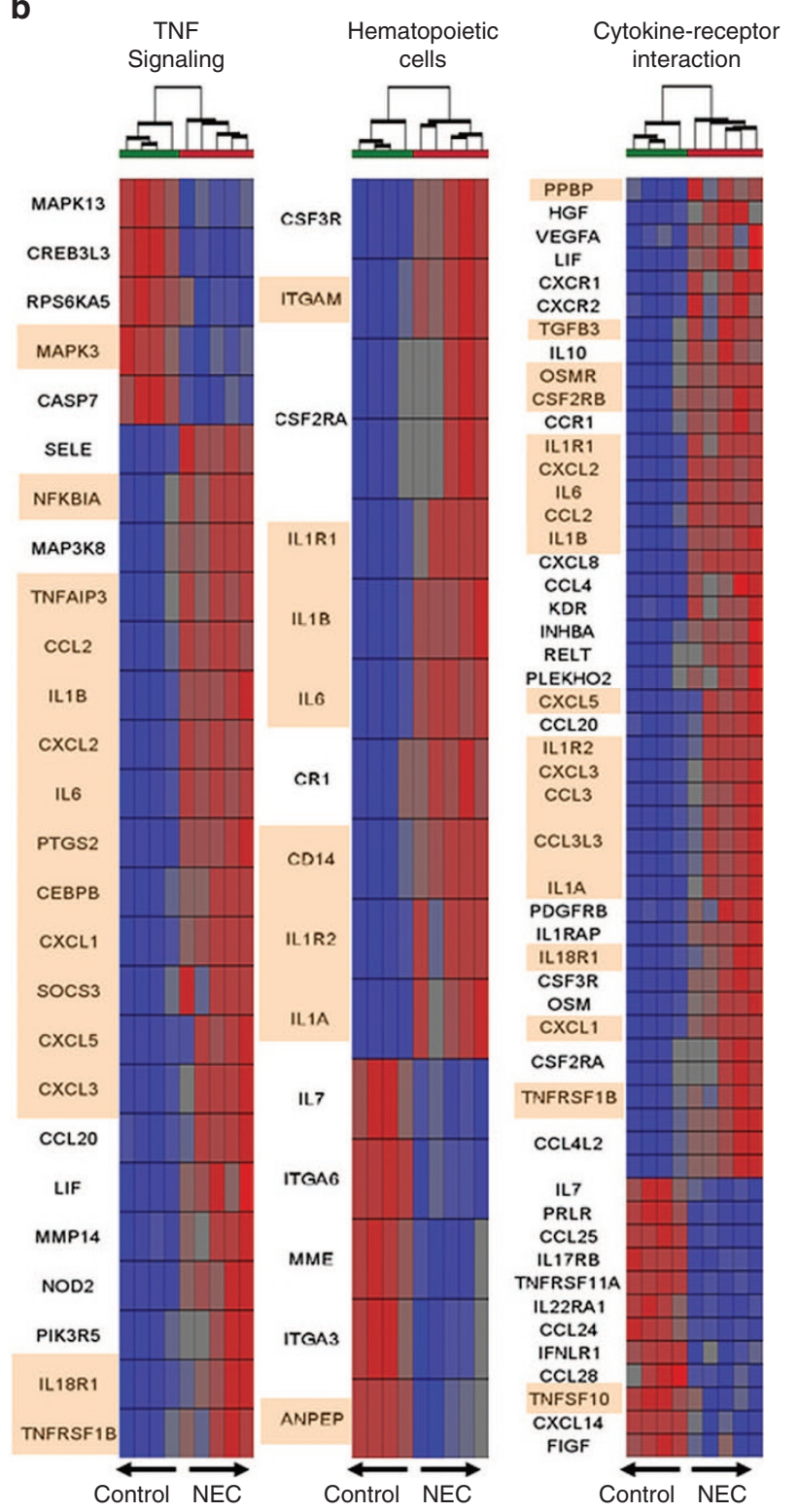

Figure 5. Top inflammatory pathways in murine 2, 4, 6-trinitrobenzene sulfonic acid (TNBS)-mediated injury and human necrotizing enterocolitis (NEC): Heat maps show the expression of differentially-expressed genes (DEGs) involved in three top inflammatory pathways: TNF-activated signaling, hematopoietic cell signaling, and cytokine-cytokine receptor interaction in (a) murine TNBS-mediated injury and (b) human NEC. In the heat maps, expression values are shown on a log scale with a range of -3 to +3 ; red boxes show upregulation, blue show downregulation, and grey indicate no change. Dendrogram above the heat map depicts hierarchical clustering of the samples (controls shown as green, injury samples red). DEGs common to both murine and human datasets are highlighted in orange. Per convention, murine gene symbols are written with the first letter in upper case and the rest in lower case. Human gene symbols are capitalized.

Similarly, GO pathways TNF signaling, hematopoietic cell signaling, and cytokine-cytokine receptor interaction were highly enriched in both the murine model as well as human NEC. These findings are consistent with the prominent cellular inflammatory response seen in murine TNBS-mediated injury as well as human NEC $(6,7,21)$. We identified several cytokines and chemokines in both murine and human datasets, including IL- $1 \alpha$, IL-1 $\beta$, IL-6, CXCL1, CXCL2, CXCL5, CCL2, and CCL3. These findings are consistent with existing data from preclinical and clinical studies on cytokine expression in plasma and tissue samples $(6,22-24)$. Increased expression of the leukocyte receptors CD14 and CD11b can be explained by the monocyte/macrophage infiltration in NEC lesions $(6,7,21,25)$. We also detected increased NF-кB1 and I $\mathrm{KB}$ expression in our murine and human datasets, which is consistent with existing information that single nucleotide polymorphisms (SNPs) of NF- $\kappa B 1$ (g.-24519delATTG) and I $\kappa B$ (g.-1004A>G) are over-represented in patients with NEC. These SNPs have been implicated in the dysregulated inflammatory reaction seen in NEC (26).

The major mechanism of cell death in TNBS-mediated injury and human NEC was apoptosis. Epithelial cell apoptosis 


\section{Murine TNBS-enterocolitis models NEC}

a

-log(P-value)
LPS/L-1 Mediated Inhibition of RXR Function
Granulocyte Adhesion and Diapedesis
PXR/RXR Activation
Hepatic Cholestasis
FXR/RXR Activation
Xenobiotic Metabolism Signaling
LXR/RXR Activation
IL-12 Signaling and Production in Macrophages
IL-17 Signaling
Toll-like Receptor Signaling
HMGB1 Signaling
PPAR $\alpha / R X R \alpha$ Activation
NRF2-mediated Oxidative Stress Response
IL-10 Signaling
Glucocorticoid Receptor Signaling
Acute Phase Response Signaling
Inhibition of Matrix Metalloproteases
IL-6 Signaling

b

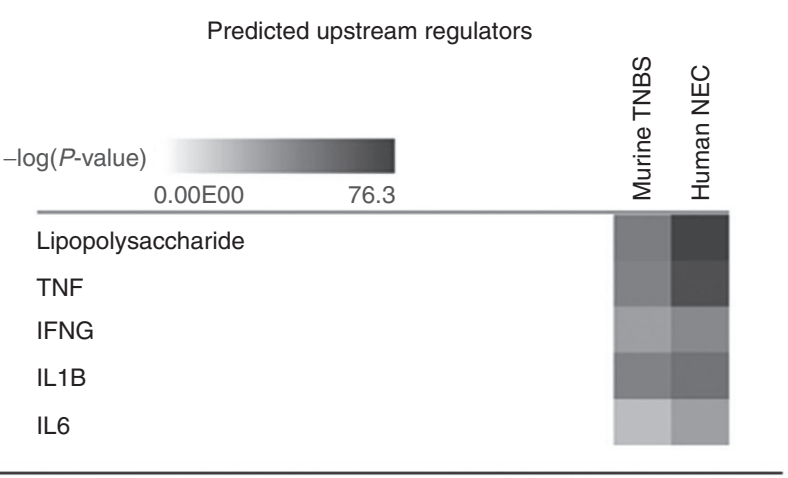

C

Top disease processes

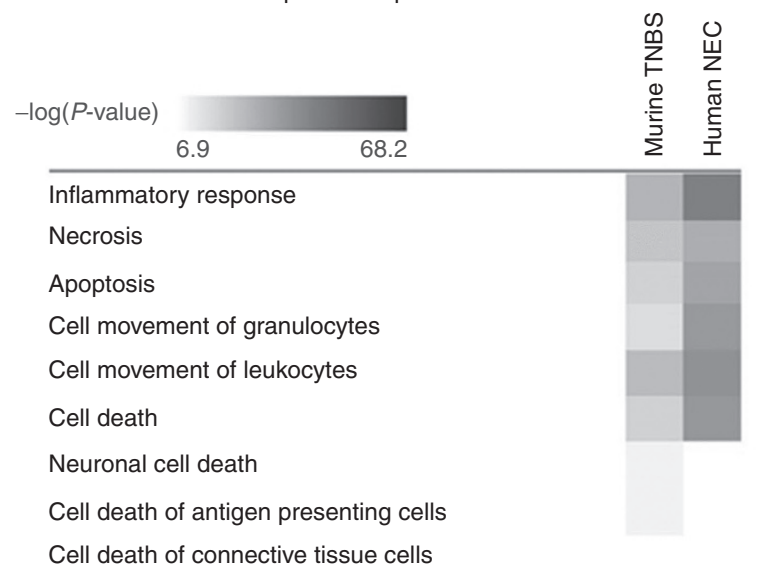

Figure 6. Comparison analysis of murine 2, 4, 6-trinitrobenzene sulfonic acid (TNBS)-mediated injury and human necrotizing enterocolitis (NEC) show a high degree of congruity in the top-ranked canonical pathways, predicted upstream regulators, and disease processes: (a) Top canonical pathways in murine TNBS-mediated injury and human NEC were depicted in a heat map that was clustered hierarchically on two axes (pathways and functions vs. condition); enrichment scores [-log (p-value); range 0 to 16.9] were depicted in grayscale; (b) Heat map shows the top predicted upstream regulators (connected to differentially-expressed genes through direct or indirect relationships) in murine and human datasets; (c) Heat map shows top disease processes in TNBS-mediated intestinal injury and human NEC.

is an early event in NEC that may initiate the more generalized bowel necrosis seen in later stages of this disease (12). Several genes in the IL-1 signaling cascade were identified in apoptotic pathways in both the murine and human datasets. IL-1 $\beta$ can induce apoptosis in cultured enterocyte cell lines (27), but this relationship is likely to be more complex. Although usually seen as pro-apoptotic mediators, IL- $1 \beta$ and its cognate receptors can also play a protective role against detachment-induced cell death in villus enterocytes (28). Clearly, further study is warranted to elucidate the role of IL-1 $\beta$ and its cognate receptors in the context of NEC.

We identified LPS as the top upstream transcriptional regulator in both TNBS-mediated intestinal injury and human NEC. These findings are consistent with the increasingly well-documented role of Gram-negative bacteria in NEC pathogenesis. Infants who develop NEC display a microbial dysbiosis that antedates the onset of NEC, with over-representation of gammaproteobacteria (including Enterobacteriaceae and Pseudomonadaceae) $(29,30)$. The central role of bacteria in NEC pathogenesis is evident from the occurrence of NEC always after postnatal bacterial colonization and never in the sterile intra-uterine microenvironment prior to birth (31). Histopathologically, bacterial overgrowth and signatures of bacterial activity such as pneumatosis, the accumulation of gaseous products of bacterial fermentation in the bowel wall, are readily evident in $\operatorname{NEC}(11,21)$. Clinically, the importance of Gram-negative bacteria in the pathogenesis of NEC is supported by evidence that enteral antibiotics such as aminoglycosides can protect against NEC and related mortality (32).

In conclusion, we have shown that murine neonatal TNBSmediated intestinal injury activates transcriptional profiles that strong resemble human NEC. The major strength of our study is in its unbiased, systems biology-based approach that acknowledges the complexity of a natural disease such as NEC. However, there are also important limitations; software applications for gene annotation and gene ontology build models by querying the known literature and are therefore, limited to known interactions and are likely to miss hitherto-unknown regulatory networks. Given these limitations, all systems biology models are, to a certain extent, incomplete. There is a need for further corroboration of these findings in preclinical models and clinical studies, which can add data on covariates such as feeding experience, comorbidities, and microbial flora. 


\section{Articles $\quad$ MohanKumaretal.}
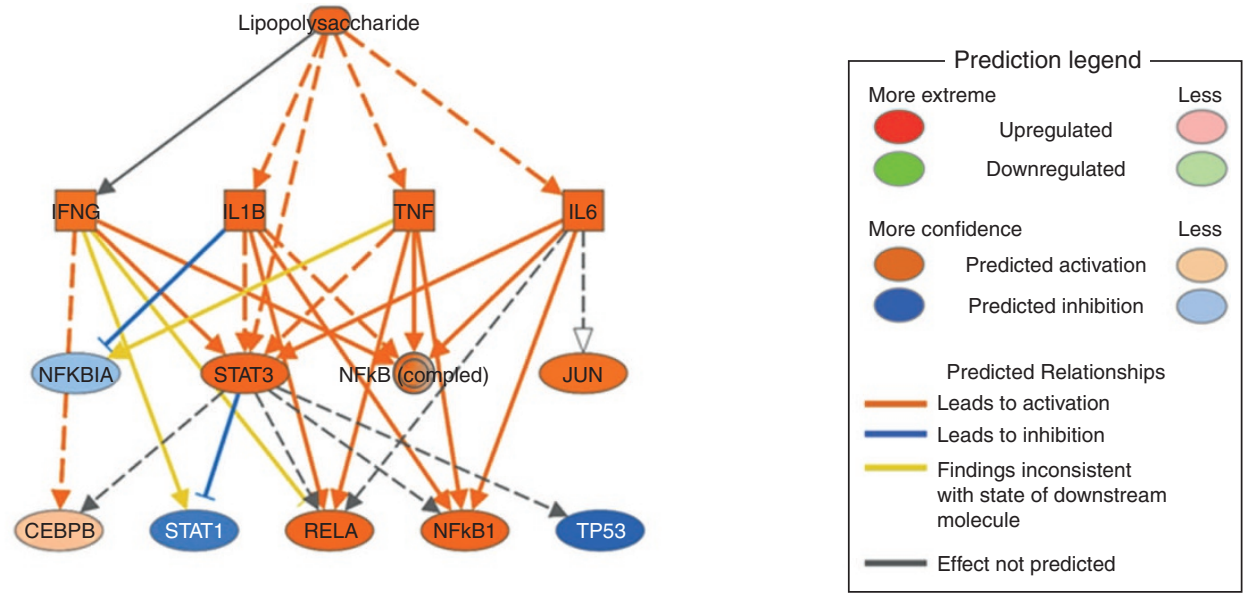

b

Human necrotizing enterocolitis

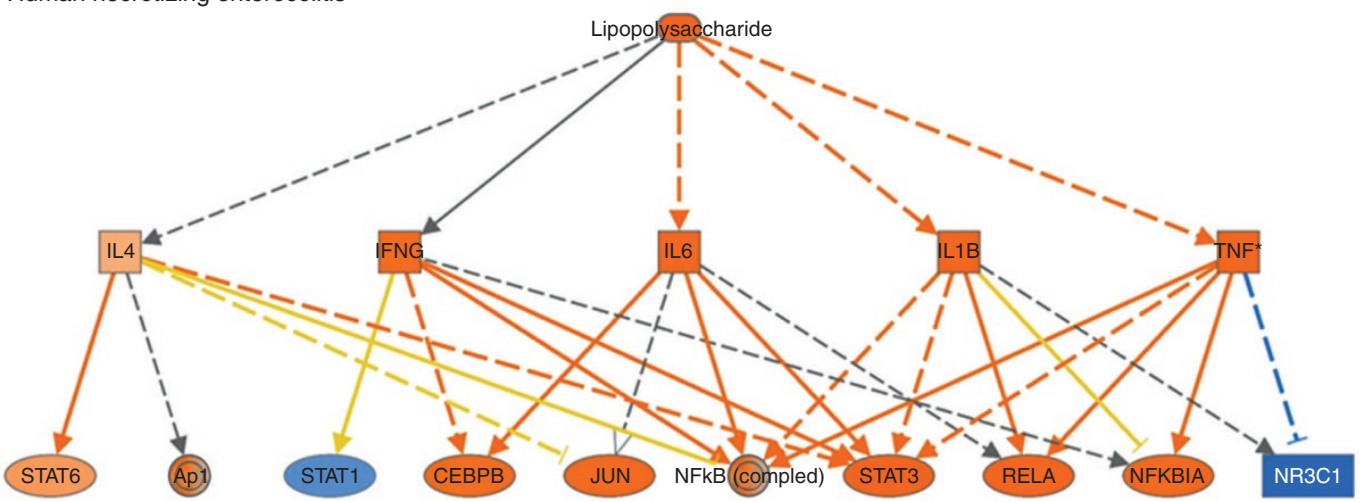

Figure 7. Lipopolysaccharide (LPS) is predicted to activate similar transcriptional networks in both murine TNBS-mediated injury and human NEC: LPS-activated gene networks in (a) murine TNBS-mediated injury and (b) human necrotizing enterocolitis (NEC). Direct relationships were shown as solid arrows, whereas broken arrows show indirect relationships. Inset: prediction legend. C/EBP- $\beta$; TP53, tumor protein 53; JUN, Jun proto-oncogene, AP-1 transcription factor subunit; LPS, lipopolysaccharide IL, interleukin; IFNG, interferon- $\gamma$; NR3C1, nuclear receptor subfamily 3, group C, member 1/glucocorticoid receptor; NFKBIA, nuclear factor of $\kappa$ light polypeptide gene enhancer in B-cells inhibitor, $\alpha$ (NFKBIA)/inhibitor of $\kappa B-\alpha($ I $K B \alpha)$; NFKB1, nuclear factor-KB-1; TNF, tumor necrosis factor; TNBS, 2, 4, 6-trinitrobenzene sulfonic acid; STAT, signal transducer and activator of transcription.

\section{METHODS}

\section{Murine Neonatal TNBS-Mediated Enterocolitis}

Animal studies were approved by the Institutional Animal Care and Use Committee at University of South Florida. As described previously (6), TNBS enterocolitis was induced in 10-d-old C57BL/6 mice $(n=11)$ by administering TNBS ( 2 equal doses of $50 \mathrm{mg} / \mathrm{kg}$ dissolved in $30 \%$ ethanol, w/v, by gavage and rectal instillation, respectively. After $24 \mathrm{~h}$, these animals were euthanized using $\mathrm{CO}_{2}$ inhalation followed by cervical dislocation. Control animals $(n=10)$ received vehicle alone. Intestinal injury was confirmed by histopathological analysis of ileocolic region (6).

\section{Tissue Preparation and Microarray Analysis}

We used a $0.5 \mathrm{~cm}$ segment of the proximal colon for analysis. RNA was extracted using TRIZOL reagent (Life Technologies, Gaithersburg, MD) and RNeasy mini kit (QIAGEN, Valencia, CA). Total RNA (100 ng) was amplified and labeled using the Ambion wholetranscript expression kit (Life Technologies) and Affymetrix WT sense target labeling kit (Affymetrix, Santa Clara, CA). Affymetrix GeneChip Mouse Transcriptome Assay 1.0 ST arrays were hybridized with $540 \mathrm{ng}$ of labeled sense DNA, washed, and stained using the FS450 Fluidic Station (Affymetrix). Fluorescent signal intensities of each stained chip were captured by the GeneChip Scanner 3000 7G System (Affymetrix).

\section{Gene-Level Expression Data From Surgically-Resected Human Tissue Samples of NEC}

Microarray results from surgically-resected bowel affected by NEC and uninflamed neonatal intestine were downloaded from the public database Gene Expression Omnibus (GEO) at the National Center for Biotechnology Information (NCBI) (33). GEO Dataset files were downloaded from ftp:// ftp.ncbi.nih.gov/pub/geo/DATA/SOFT/GDS/ and uncompressed from.gz compression format. These tissue samples (NEC, $n=5$; accession numbers GSM1661796, GSM1661797, GSM1661798, GSM1661799, GSM1133300; and uninflamed neonatal intestine, $n=4$; accession numbers GSM1133306, GSM1133307, GSM1133308, GSM1133309) have been described earlier (34). In this study, the authors obtained surgically-resected specimens of NEC (26.4-31.4 wk gestation) and uninflamed intestine $(32.3-37.9 \mathrm{wk}$ gestation, operated for intestinal obstruction or ileostomy closure). Standard Affymetrix protocols were followed for RNA extraction and hybridization of Human Gene 1.0 ST arrays (Affymetrix). Tissue specimens were validated by histopathology and mRNA expression by polymerase change reactions.

\section{Microarray Data Analysis}

Gene expression data were imported as.CEL files into the Partek Genomics Suite v6.6 (Partek, St Louis, MO). Raw data were processed by the Robust Multi-array Average method that involved quantile normalization, background correction, median polish probe 
Table 5. Comparison of TNBS-induced enterocolitis in mouse pups vs. TNBS-induced colitis in adult mice

\begin{tabular}{|c|c|c|}
\hline & TNBS-induced enterocolitis in murine pups & TNBS-induced colitis in adult mice \\
\hline Procedure & $\begin{array}{l}\text { One-time administration of TNBS ( } 2 \text { identical doses of } 50 \mathrm{mg} / \\
\mathrm{kg} \text { dissolved in } 30 \% \text { ethanol, administered by gavage and rectal } \\
\text { instillation, respectively) }\end{array}$ & $\begin{array}{l}\text { Usually induced by one-time rectal instillation of TNBS ( } 0.5-6 \mathrm{mg} / \\
\text { mouse, dissolved in } 35-50 \% \text { ethanol). Chronic colitis can be } \\
\text { induced by repeated intra-rectal applications of TNBS dissolved in } \\
\text { ethanol, administered at weekly intervals }\end{array}$ \\
\hline Mouse strains & $\begin{array}{l}\text { C57BL/ } 6 \text { pups develop severe injury; strains such as } 129 \mathrm{SvEv} \text { are } \\
\text { also highly-susceptible }\end{array}$ & $\begin{array}{l}\text { C57BL/ } 6 \text { mice are relatively resistant to TNBS. Strains such as } \mathrm{C} 3 \mathrm{H} / \\
\mathrm{HeJ}, \mathrm{SJL} / \mathrm{J} \text {, and Balb/c are more sensitive }\end{array}$ \\
\hline $\begin{array}{l}\text { Regional } \\
\text { predilection }\end{array}$ & Distal ileum, cecum, and proximal colon & Distal colon \\
\hline $\begin{array}{l}\text { Temporal } \\
\text { evolution }\end{array}$ & $\begin{array}{l}\text { Acute necrotizing enterocolitis evident at } 12 \mathrm{~h} \text {. Injury peaks at } \\
18-24 \mathrm{~h} \text { with }>50 \% \text { mortality. In survivors, mucosal injury starts to } \\
\text { resolve at } 48 \mathrm{~h} \text {. Histopathology shows necrosis, macrophage-rich } \\
\text { infiltrates, and focal hemorrhages }\end{array}$ & $\begin{array}{l}\text { Acute transmural inflammation within a few hours. Slower, } \\
\text { subacute progression. Focal areas of necrosis, mononuclear } \\
\text { infiltration, and basal cryptitis develops in 2-3 d. Mucosal } \\
\text { inflammation persists for up to } 2-3 \text { wk. }\end{array}$ \\
\hline $\begin{array}{l}\text { Cellular } \\
\text { inflammatory } \\
\text { response }\end{array}$ & $\begin{array}{l}\text { Monocytes/macrophages (nearly } 70 \% \text { ), some neutrophils } \\
(20-25 \%) \text {, but very few lymphocytes }\end{array}$ & Pleomorphic response; abundant $\mathrm{CD} 4^{+} \mathrm{Th} 1$ and Th 17 lymphocytes \\
\hline $\begin{array}{l}\text { Cytokine } \\
\text { expression in } \\
\text { affected tissues }\end{array}$ & IL-1 $\alpha$, IL-1 $\beta$, chemokines CXCL2, CXCL5, CCL3, CCL4 & Interferon- $\gamma$, TNF, IL-2, and IL-12p70 \\
\hline Mechanism(s) & $\begin{array}{l}\text { Unclear. Administration of ethanol or TNBS alone does not cause } \\
\text { injury. Ethanol is believed to increase the permeability of the } \\
\text { epithelial barrier, allowing TNBS to reach the lamina propria. } \\
\text { Germ-free pups remain unaffected, indicating that the injury } \\
\text { develops only in the presence of luminal microflora and is not } \\
\text { due to chemical/corrosive action of TNBS }\end{array}$ & $\begin{array}{l}\text { TNBS is believed to haptenize microbial- and self-proteins to } \\
\text { render them immunogenic. Inflammatory response during first } \\
5-6 \mathrm{~d} \text { believed to represent a delayed-type hypersensitivity } \\
\text { response }\end{array}$ \\
\hline
\end{tabular}

TNBS, 2, 4, 6-trinitrobenzene sulfonic acid.

set summarization, and $\log _{2}$ transformation to bring mean expression values to the same scale (35). Expression values from two control and three TNBS tissues were excluded in view of failure to pass quality control checks (36). Consequently, we used expression data from eight control and eight TNBS tissues in all downstream analyses. For comparison with human NEC, we uploaded.CEL datasets from five patients with NEC and four with uninflamed neonatal intestine. Average expression levels were distributed similarly across all samples.

\section{DEGs}

Gene expression between TNBS vs. control, and NEC vs. uninflamed neonatal intestine was compared by one-way ANOVA on all probe sets processed by a robust multi-array procedure, combined with Fisher's least significant difference method for group-wise comparisons (37) and the Benjamini-Hochberg step-up procedure to identify false positives (38). To identify the DEGs, we set the thresholds for the false discovery rate at $<0.05$ and fold change $\geq 1.5$. Hierarchical clustering analysis was performed on the DEGs using Partek default settings. Correlation statistics for murine and human orthologous genes were computed using the software program GraphPad Prism (version 7.00; GraphPad, La Jolla, CA).

\section{Gene Ontology and Network Analysis}

The DEGs in murine and human samples were separately assigned to gene ontology (GO) categories using GO Enrichment analysis (Partek). The enriched GO biological processes were validated using the web-based tool DAVID (National Cancer Institute, Frederick, MD) (10). To identify enriched pathways and transcriptional networks, the DEGs were further analyzed using the Pathway Enrichment module within Partek, which utilizes the KEGG databases (Kyoto Encyclopedia of Genes and Genomes) (9) to rank the DEGs by enrichment score (-log ( $P$-value) derived from the contingency table; Fisher's Exact test).

The list of DEGs selected by the microarray analysis was then loaded separately in the web-based software application Ingenuity Pathway Analysis (QIAGEN, Redwood City, CA) to look for direct and indirect relationships at $P<0.05$ and experimental fold-change $\geq \pm 1.5$. The data were computed to identify transcriptional networks associated with specific biological functions, diseases and signaling pathways (39). To estimate the degree of similarity between the GO pathways and biological processes activated in the murine and human datasets, we used the "comparison analysis" tool within the application (39).

\section{SUPPLEMENTARY MATERIAL}

Supplementary material is linked to the online version of the paper at http:// www.nature.com/pr

\section{AUTHOR CONTRIBUTIONS}

A.M. designed the study and wrote the manuscript. K.M., K.N., F.C., R.H.Y.J., and B.T. performed key experiments or data analysis. All the authors contributed to and approved the manuscript.

\section{STATEMENT OF FINANCIAL SUPPORT}

This study was supported by National Institutes of Health awards HD059142 and HL124078 (to A.M.).

Disclosure: The authors disclose no conflicts.

\section{REFERENCES}

1. Patel RM, Kandefer S, Walsh MC, et al.; Eunice Kennedy Shriver National Institute of Child Health and Human Development Neonatal Research Network. Causes and timing of death in extremely premature infants from 2000 through 2011. N Engl J Med 2015;372:331-40.

2. Kasivajjula H, Maheshwari A. Pathophysiology and current management of necrotizing enterocolitis. Indian J Pediatr 2014;81:489-97.

3. Sharma R, Hudak ML, Tepas JJ 3rd, et al. Impact of gestational age on the clinical presentation and surgical outcome of necrotizing enterocolitis. J Perinatol 2006;26:342-7.

4. Yee WH, Soraisham AS, Shah VS, Aziz K, Yoon W, Lee SK; Canadian Neonatal Network. Incidence and timing of presentation of necrotizing enterocolitis in preterm infants. Pediatrics 2012;129:e298-304.

5. Llanos AR, Moss ME, Pinzòn MC, Dye T, Sinkin RA, Kendig JW. Epidemiology of neonatal necrotising enterocolitis: a population-based study. Paediatr Perinat Epidemiol 2002;16:342-9.

6. MohanKumar K, Kaza N, Jagadeeswaran R, et al. Gut mucosal injury in neonates is marked by macrophage infiltration in contrast to pleomorphic 


\section{Articles $\mid$ MohanKumar etal.}

infiltrates in adult: evidence from an animal model. Am J Physiol Gastrointest Liver Physiol 2012;303:G93-102.

7. MohanKumar K, Namachivayam K, Chapalamadugu KC, et al. Smad7 interrupts TGF- $\beta$ signaling in intestinal macrophages and promotes inflammatory activation of these cells during necrotizing enterocolitis. Pediatr Res 2016;79:951-61.

8. Ashburner M, Ball CA, Blake JA, et al. Gene ontology: tool for the unification of biology. The Gene Ontology Consortium. Nat Genet 2000;25:25-9.

9. Kanehisa M, Sato Y, Kawashima M, Furumichi M, Tanabe M. KEGG as a reference resource for gene and protein annotation. Nucleic Acids Res 2016;44(D1):D457-62.

10. Huang da W, Sherman BT, Lempicki RA. Systematic and integrative analysis of large gene lists using DAVID bioinformatics resources. Nat Protoc 2009;4:44-57.

11. Bucher BT, McDuffie LA, Shaikh N, et al. Bacterial DNA content in the intestinal wall from infants with necrotizing enterocolitis. J Pediatr Surg 2011;46:1029-33.

12. Jilling T, Lu J, Jackson M, Caplan MS. Intestinal epithelial apoptosis initiates gross bowel necrosis in an experimental rat model of neonatal necrotizing enterocolitis. Pediatr Res 2004;55:622-9.

13. Alex P, Zachos NC, Nguyen T, et al. Distinct cytokine patterns identified from multiplex profiles of murine DSS and TNBS-induced colitis. Inflamm Bowel Dis 2009;15:341-52.

14. Jilling T, Simon D, Lu J, et al. The roles of bacteria and TLR4 in rat and murine models of necrotizing enterocolitis. J Immunol 2006;177:3273-82.

15. Tian R, Liu SX, Williams $C$, et al. Characterization of a necrotizing enterocolitis model in newborn mice. Int J Clin Exp Med 2010;3:293-302.

16. Liu SX, Tian R, Baskind H, Hsueh W, De Plaen IG. Platelet-activating factor induces the processing of nuclear factor-kappaB p105 into p50, which mediates acute bowel injury in mice. Am J Physiol Gastrointest Liver Physiol 2009;297:G76-81.

17. Maheshwari A, Christensen RD, Calhoun DA, Dimmitt RA, Lacson A. Circulating CXC-chemokine concentrations in a murine intestinal ischemia-reperfusion model. Fetal Pediatr Pathol 2004;23:145-57.

18. Walthall K, Cappon GD, Hurtt ME, Zoetis T. Postnatal development of the gastrointestinal system: a species comparison. Birth Defects Res B Dev Reprod Toxicol 2005;74:132-56.

19. Nanthakumar NN, Dai D, Meng D, Chaudry N, Newburg DS, Walker WA. Regulation of intestinal ontogeny: effect of glucocorticoids and luminal microbes on galactosyltransferase and trehalase induction in mice. Glycobiology 2005;15:221-32.

20. Tepas JJ 3rd, Sharma R, Leaphart CL, Celso BG, Pieper P, Esquivia-Lee V. Timing of surgical intervention in necrotizing enterocolitis can be determined by trajectory of metabolic derangement. J Pediatr Surg 2010;45:310-3; discussion 313-4.

21. Remon JI, Amin SC, Mehendale SR, et al. Depth of bacterial invasion in resected intestinal tissue predicts mortality in surgical necrotizing enterocolitis. J Perinatol 2015;35:755-62.

22. Maheshwari A, Schelonka RL, Dimmitt RA, et al.; Eunice Kennedy Shriver National Institute of Child Health and Human Development Neonatal Research Network. Cytokines associated with necrotizing enterocolitis in extremely-low-birth-weight infants. Pediatr Res 2014;76:100-8.
23. Harris MC, Costarino AT Jr, Sullivan JS, et al. Cytokine elevations in critically ill infants with sepsis and necrotizing enterocolitis. J Pediatr 1994;124:105-11.

24. Ng PC, Li K, Wong RP, et al. Proinflammatory and anti-inflammatory cytokine responses in preterm infants with systemic infections. Arch Dis Child Fetal Neonatal Ed 2003;88:F209-213.

25. Remon J, Kampanatkosol R, Kaul RR, Muraskas JK, Christensen RD, Maheshwari A. Acute drop in blood monocyte count differentiates NEC from other causes of feeding intolerance. J Perinatol 2014;34:549-54.

26. Sampath V, Le M, Lane L, et al. The NFKB1 (g.-24519delATTG) variant is associated with necrotizing enterocolitis (NEC) in premature infants. J Surg Res 2011;169:e51-7.

27. Wright K, Kolios G, Westwick J, Ward SG. Cytokine-induced apoptosis in epithelial HT-29 cells is independent of nitric oxide formation. Evidence for an interleukin-13-driven phosphatidylinositol 3-kinase-dependent survival mechanism. J Biol Chem 1999;274:17193-201.

28. Waterhouse CC, Joseph RR, Stadnyk AW. Endogenous IL-1 and type II IL-1 receptor expression modulate anoikis in intestinal epithelial cells. Exp Cell Res 2001;269:109-16.

29. Wang Y, Hoenig JD, Malin KJ, et al. 16S rRNA gene-based analysis of fecal microbiota from preterm infants with and without necrotizing enterocolitis. ISME J 2009;3:944-54.

30. Warner BB, Deych E, Zhou Y, et al. Gut bacteria dysbiosis and necrotising enterocolitis in very low birthweight infants: a prospective case-control study. Lancet 2016;387:1928-36.

31. Hsueh W, Caplan MS, Tan X, MacKendrick W, Gonzalez-Crussi F. Necrotizing enterocolitis of the newborn: pathogenetic concepts in perspective. Pediatr Dev Pathol 1998;1:2-16.

32. Bury RG, Tudehope D. Enteral antibiotics for preventing necrotizing enterocolitis in low birthweight or preterm infants. Cochrane Database Syst Rev 2001:CD000405.

33. Edgar R, Domrachev M, Lash AE. Gene Expression Omnibus: NCBI gene expression and hybridization array data repository. Nucleic Acids Res 2002;30:207-10.

34. Chan KY, Leung KT, Tam YH, et al. Genome-wide expression profiles of necrotizing enterocolitis versus spontaneous intestinal perforation in human intestinal tissues: dysregulation of functional pathways. Ann Surg 2014;260:1128-37.

35. Irizarry RA, Hobbs B, Collin F, et al. Exploration, normalization, and summaries of high density oligonucleotide array probe level data. Biostatistics 2003;4:249-64.

36. Affymetrix White Paper: Quality Assessment of Exon and Gene Arrays, Revision 1.1, 2007. (http://media.affymetrix.com/support/technical/ whitepapers/exon_gene_arrays_qa_whitepaper.pdf).

37. Hayter AJ. The Maximum Familywise Error Rate of Fisher's Least Significant Difference Test. J Am Stat Assoc 1986;81:1000-1004.

38. Benjamini Y, Drai D, Elmer G, Kafkafi N, Golani I. Controlling the false discovery rate in behavior genetics research. Behav Brain Res 2001;125: $279-84$.

39. Krämer A, Green J, Pollard J Jr, Tugendreich S. Causal analysis approaches in Ingenuity Pathway Analysis. Bioinformatics 2014;30:523-30. 